\title{
TITLE:
}

\section{An Inaugural Address by Toshisada Nishida Professor of Kyoto University}

$\operatorname{AUTHOR}(\mathrm{S})$ :

\section{CITATION:}

An Inaugural Address by Toshisada Nishida Professor of Kyoto University. Pan Africa News 1995, 2(1): 3-4

ISSUE DATE:

1995-06

URL:

http://hdl.handle.net/2433/143316

\section{RIGHT:}

Copyright (C) Pan Africa News. 
monograph recording 25 years of research in the Mahale Mountains, Nishida has described Mahale as being biogoegraphically one of the most interesting regions in East Africa, with its animal and plant communities showing similarities to those of West Africa. Besides the chimpanzee there are other interesting primates including the Angolan black and white colobus which is not found anywhere else in Tanzania.

Also there are many endemic species of insects (butterflies, beetles, bees etc.) - species not found anywhere else in the world. All in all the number of mammals recorded at Mahale are as follows:

$\begin{array}{lc}\text { Primates } & 9 \\ \text { Pangolins } & 1 \\ \text { Rodents } & 9 \\ \text { Carnivores } & 16 \\ \text { Hippopotamus } & 1 \\ \text { Ungulates } & 7 \\ \text { Aardvark } & 1 \\ \text { Elephant } & 1 \\ \text { Dassie } & 2 \\ \text { Zebra } & 1 \\ \text { Pigs } & 2\end{array}$

(Not much is known about bats, shrews and some rodents).

One point worth noting is that the Japanese pioneers of this sustained 30 years research at Mahale, notably Itani, Nishida, Uehara, Takahata, Hiraiwa - Hasagawa, Kawanaka, Hayaki, Takasaki, Hesegawa and Kano to mention but a few, have always worked closely with the local people of Mahale. Thus, a checklist of names of plants, animals, insects, fish and birds of Mahale has been compiled and published in Japanese, Kitongwe and English. The Society plans to support and encourage this kind of research.

I have tried briefly to indicate the unique attributes of Mahale with its rich fauna and flora and accumulated data on chimpanzees obtained over a period of 30 years. Mahale needs to be protected as it is one of the world's best field laboratories for the study of Man's closest relatives. One of the objectives of the Society therefore, will be to support, wherever possible, field researchers and conservationists wishing to carry out research in Mahale. The kind of support will be determined as the Society grows and resources become available.

In conclusion, let me once again thank all of you for the support and honour you have given us in being with us at the inauguration of our Society this evening. We hope you will continue to show interest. We will keep you informed of the Society's achievements and accomplishments.

I thank you for your attention.

\section{An Inaugural Address by Toshisada Nishida Professor of Kyoto University}

Good afternoon Ladies and Gentlemen.

Today I am very happy to meet here with many people who understand the importance of wildlife conservation.

I have been studying the wild chimpanzees of the Mahale Mountains for almost three decades now. Allow me to explain why I have been involved with only one species of animal for such a long time. Chimpanzees have proved to be very charming animals who are so like us. For example, adult male chimpanzees have their own political strategies.

The current alpha male, Ntologi, is almost 40 years old but he has been able to keep his top position for as long as 15 years. At his side is his young, energetic rival, second-ranking Nsaba who wishes to take over the alpha status as such a position confers priority of matings with females and priority of access to delicious foods such as meat and ripe figs.

How can Ntologi maintain his top position for so many years despite his old age?

First, he often performs very impressive displays including rock-throwing, charging, branchdragging, branch-shaking, stamping or slapping tree butresses and so on. By combining these displays in his own unique way, he has succeeded in intimidating even the younger, physically stronger males.

Second, he has maintained his alliances with other males by grooming them earnestly and by sharing his meat with them. 
Third, as soon as he notices his rival grooming other adult males, he charges against them and prevents the formation of an alliance.

I want to stress that the behaviour of chimpanzees is flexible, complex and variable, so that even after 20 years of research we still witness behaviours that are new to us. Let me explain the most recent example. A 3 year old unweaned female, Pipi, lost her mother because of influenza last year. She was cared for by as many as six older chimpanzees in succession. These foster mothers and fathers have provided all the necessary protection for the orphan Pipi except lactation. Thus, wild chimpanzees have a kind of social compensation system. So, during this field season I have observed an orphan survive her mother's death.

During our long-term study, we have met with difficulties in continuing research and conservation, in particular due to lack of funds. To continue research and conservation we need basic facilities and equipment such as staff housing, various types of boats, engines, generators and solar panels. We also need funds to train the young members of our staff and to invite young Tanzanian scientists. By establishing the Mahale Wildlife Conservation Society we are able to supplement the activities of TANAPA, SWRI and our team.

In addition, I have many dreams for the future. In reciprocation to the hospitality and cooperation extended to us by the Tanzanian people and government we would like to use our expert knowledge on chimpanzeees and other wildlife for conservation, public education and in the assistance of
Tanzanian students.

If we succeed in raising enough funds in the Society, I would like to propose the following projects:

1. The publication of a newsletter for the conservation of chimpanzees entitled "Pan Africa News".

2. The publication of a guidebook on the wildlife of Mahale Mountains National Park.

3. Deploying a capable volunteer for monitoring the numbers of animals and for educating local assistants. 4. Sending a veterinarian to investigate diseases of the animals, chimpanzees in particular.

5. Eradicating weed trees, mjoholo (Cassia) that have been prosperous at the cost of indigenous vegetation in the Mahale Park.

6. Establishment of a small museum for public education, tourism and research equipped with computers and a library.

7. Enterprises to commemorate 30 years of research in Mahale next year including public lectures, a photo and panel exhibition and video presentations.

Of course there are many other activities conceivable. We would be very grateful if you would suggest to us pertinent and feasible proposals.

Finally, I sincerely thank Professor Hosea Kayumbo for his leadership in organising the Society, Mr. Toshimichi Nemoto for his ideas, network information and communication, Mr. Edeus Massawe for drafting the articles of the Society and Mr. Olomi for his great secretarial work. I also would like to thank all the parties present here for their enthusiasm for wildlife conservation.

Thank you. 